\title{
Nanometrology, Standardization and Regulation of Nanomaterials in Brazil: a Proposal for an Analytical-Prospective Model
}

\author{
Ana Rusmerg Giménez Ledesma', Maria Fatima Ludovico de Almeida²
}

\begin{abstract}
The main objective of this paper is to propose an analytical-prospective model as a tool to support decision-making processes concerning metrology, standardization and regulation of nanomaterials in Brazil, based on international references and ongoing initiatives in the world. In the context of nanotechnology development in Brazil, the motivation for carrying out this research was to identify potential benefits of metrology, standardization and regulation of nanomaterials production, from the perspective of future adoption of the model by the main stakeholders of development of these areas in Brazil. The main results can be summarized as follows: (i) an overview of international studies on metrology, standardization and regulation of nanomaterials, and nanoparticles, in special; (ii) the analytical-prospective model; and (iii) the survey questionnaire and the roadmapping tool for metrology, standardization and regulation of nanomaterials in Brazil, based on international references and ongoing initiatives in the world.
\end{abstract}

Keywords: metrology; standardization; regulation; nanotechnology; nanomaterials; nanoparticles; roadmapping; brazil.

'Peers Business and Process Consulting,Av. Jurucê, 194, I st floor, São Paulo, Brazil, 04080-0 I0. Phone: 0552199 II 6779.

E-mail: anagimnz@yahoo.com

2Master Program on Metrology, Quality and Innovation; Pontifical Catholic University of Rio de Janeiro; Rua Marquês de São Vicente, 225, Rio de Janeiro, Brazil, 2247I-I 50. Phone: 0552I 3527I542. E-mail: fatima.ludovico@puc-rio.br 


\section{Introduction}

Nanomaterials are widely seen as having huge potential to bring benefits to many areas of research and application, and nanotechnology - as a knowledge and business field - has been attracting increasing investments from governments and firms around the world. However, it has been also recognized that applications of nanomaterials, and in particular of nanoparticles, may raise new challenges in safety, regulatory and ethical domains. These issues require societal debate with respect to the increase or decrease of risks related to the particle size and surface properties of nanomanipulated materials. From this perspective, in 2003 the UK Government commissioned the Royal Society and the Royal Academy of Engineering to carry out an independent study into current and future developments in nanoscience and nanotechnology and their impacts (The Royal Society/ The Royal Academy of Engineering, 2004).

More recently, a stream of innovative products that exploit new physical, chemical and biological properties in nanoscale has raised concerns about their appropriate regulation. They are partially due to uncertainties about environmental and human safety impacts of materials with such properties, and also because regulatory agencies have committed themselves to promoting the responsible development of the nanotechnology. Despite the fact that environmentally beneficial products and applications have been encouraged by regulatory institutions, there is a need to understand the wider governance of nanotechnology: how it might be conceptualised, studied, and, in practice, steered so as to purposefully influence the direction of innovation (Zwanenberg et al., 2008).

As a matter of fact, much more information has become available about nanoscience and nanotechnology development in the last 10 years and several activities and initiatives have been addressed to assess the impacts and risks of nanomaterials and nanoparticles on human health and the environment. By way of illustration, there are several programmes and networks for nanotechnology existing in the European Union and USA, many of which are involved and investing in nanometrology and standardization related projects. From these initiatives, we highlight the following: (i) the ISO TC 229 Technical Committee on nanotechnologies, which aims to develop internationally agreed definitions, standards and metrology techniques related to nanotechnology, at international level; (ii) a voluntary code - the Responsible NanoCode - proposed by the Royal Society, Insight Investment and the Nanotechnology Industries Association (NIA) in the United Kingdom; (iii) since its creation in 2006, the OECD Working Group on Nanomaterials has been working in relevant issues concerning environmental and human safety impacts of nanomaterials; and (iv) the
Nano Risk Framework was launched in 2007, as a result of a joint effort between the US Environmental Defense Fund and DuPont; and (v) the European Nanotechnology Gateway (Nanoforum). All these initiatives seek to ensure that industrial development and innovations based on future nanotechnologies will be conducted in a safe, responsible and sustainable mode.

Nanometrology underpins all nanotechnologies because it allows the characterization of materials in terms of dimensions and also in terms of attributes such as electrical properties and mass. Greater precision in metrology will assist the development of nanoscience and nanotechnologies. However, this will require increased standardization to allow calibration of equipment and conformity assessment of novel products and processes. Despite international studies indicating the existence of numerous efforts aimed at developing nanometrology techniques, standards regarding nanotechnology nomenclature, and codes of conduct (instruments of self-regulation), there is still a broad development space for new nanometrology techniques, standards, technical regulations and harmonized procedures aimed at effective and safe diffusion of innovation based on nanotechnology and nanoscience. This scenario pointing towards the urgent need for experimental studies and diagnosis concerning nanometrology, standardization and regulation of nanotechnologies, and in particular of nanomaterials.

Legislation focusing on nanotechnology is undergoing a shift at global level, since standardization ceases to be voluntary to become mandatory. The United States of America and European Community countries have been developing harmonized legislation and some emerging countries, like Brazil, seek to participate in international standardization initiatives, to consolidate their national technical infrastructure for nanotechnology and nanoscience future development, as well as to establish regulatory frameworks at national level (ABDI/CGEE, 20I0).

Focusing on the Brazilian context, in 2005, the Government established the National R\&D Programme in Nanotechnology, with the objectives of (i) developing niche markets with potential for competitiveness in electronic, medical and pharmaceutical materials, equipment and tools, and nanostructured tissues, and (ii) expanding the access of local industry to emerging frontiers in nanotechnology research and innovation. This Program focused on four main challenges: (i) institutional incentives to technology-based companies, (ii) expansion of human resources and competences base in nanotechnology, (iii) investment in R\&D; and (iv) adequacy of the regulatory framework (Brazil, 2005).

Four years later, the Competitiveness Forum of Nanotechnology was launched as a strategic mechanism to support 
the debate and to promote initiatives and programs aligned to the National Industrial Policy and to the National R\&D Programme in Nanotechnology (Brasil, 2010). In general, this Forum seeks consensus on opportunities and challenges in nanotechnology, and defines goals and actions for reviewing issues in the National Industrial Policy concerning nanotechnology challenges (Brazil, 2010). To accompany the Forum purposes and its operationalization, four working groups (WG) were formed, as follows: (i)WG on Regulatory Framework; (ii) WG on Market; (iii) WG on International Cooperation, and (iv) WG on Human Resources and Competences (Brazil, 20I0).

Inasmuch as rules and regulations provide equitable conditions in markets and promote international trade flows, it is believed that the definition of a regulatory framework in Brazil for nanotechnology development and the adoption of the main nanometrology techniques and standards applicable to nanomaterials will provide better conditions for Brazilian industry to compete internationally. The competitive insertion of the country in this field will depend on exports of innovative products and materials developed and manufactured according to safe, integrated and responsible strategies.

Within this context, the objective of this paper is to propose an analytical-prospective model as a tool to support decision-making processes concerning metrology, standardization and regulation of nanomaterials in Brazil, based on international references and ongoing initiatives in the world. The motivation for carrying out this research was to identify potential benefits of metrology, standardization and regulation of nanomaterials production, from the perspective of future adoption of the model by the main stakeholders of development of these areas in Brazil. In our vision, this model can help public and business managers to formulate public policies and innovation strategies aimed at an integrated, safe and responsible development and use of nanomaterials in the country. It seeks to highlight the importance and benefits to the country of nanometrology, standardization and regulation of nanomaterials, and its results are addressed to the major stakeholders engaged in safe and responsible development, production and commercialization of nanomaterials, with special attention to the members of the WG on Regulatory Framework.

\section{Methodology}

The research methodology encompassed: (i) bibliographical and documentary review on nanometrology, standardization and regulation of nanomaterials; (ii) survey and content analysis of international studies and normative references related to these themes, and (iii) development of a conceptual model that integrates the three functions - nanometrology, standardization and regulation of nanomaterials - based on international benchmarks and initiatives around the world. Content analysis of international studies and normative references pointed to the choice of the analytical frameworks adopted in two studies, namely: (i) Nano-Strand project, developed within the European Community (Nano-Strand, 2006; 2007), and (ii) a study entitled "An Overview of the Framework of Current Regulation Affecting the Development and Marketing of Nanomaterials ", authored by Frater et al (2006). Complementarily, a third study provided an overview of the main initiatives concerning standardization, regulation and self-regulation carried out in several countries. The third study entitled "Developments in Nanotechnologies Regulation and Standards" was published by Observatory Nano, in 2010. It reports relevant actions in European countries, USA, Canada, Japan, China, India, Australia and Taiwan.

Taking both frameworks as a starting point for developing the analytical-prospective model, we identified a need for: (i) adapting to the Brazilian context the issues of nanometrology, standardization and regulation of nanomaterials, (ii) integrating the three functions, since the adopted frameworks focused only on one or two functions; and (iii) including a prospective module, with support of strategic roadmapping tools, considering the long-term perspective inherent to complex and uncertain environments as in the case of emergent technologies development. The insertion of the prospective module was based on previous works by Phaal et al (2004) and Rinne (2004). It was sought to offer a conceptual and didactic framework to reveal and organize the uncertainties and challenges inherent to the evolution of the three functions discussed here, in a long-term horizon and in the context of an emerging country.

\section{Conceptualization of the Techno-Scientific Para- digm of Nanotechnology}

We present in this section some signs of the new technoscientific paradigm based on the development of nanotechnology, comprising: (i) scientific production; (ii) intellectual property, and (iii) ongoing research in nanometrology, standardization and regulation of nanotechnologies.

Before going any further, we introduce the concepts of scientific and technological paradigm, according to Kuhn (1962) and Dosi (1982), respectively.

Kuhn (1962) defines scientific paradigm as a "constellation of achievements", incorporating concepts, values and techniques that are shared by a particular scientific community and used to define problems and find solutions. The concept of scientific paradigm is associated with the emergence of "competitive procedures", which require technological

ISSN: 07 I8-2724. (http://www.jotmi.org)

Journal of Technology Management \& Innovation (c) Universidad Alberto Hurtado, Facultad de Economía y Negocios. 
discontinuity and the convergence of independent flows of know-how.

Figure I represents the evolution of a emerging knowledge from the point where the results of scientific research seem promising for future technological developments, until the introduction of competitive applications into markets (Day et al, 2003).

Particularly, the area between the intersections titled "competitive modalities" and "competitive applications" represents the greatest challenges of innovation management. Within the context discussed in this paper, it can be interpreted as a broad development space for nanometrology, standardization and regulation of nanotechnology, since these functions have been considered as a fundamental support for competitive applications offered by economic agents.

Focusing on the techno-scientific paradigm of nanotechnology, it seems to bring together a set of technologies with great potential for economic transformation, through patterns and technological trajectories as defined by Dosi (1982). As represented in Figure 2, the concepts of "technological development" and "competitive applications" are directly associated to these patterns and technological trajectories.

\section{Scientific Production}

Figure 2 shows the evolution of the number of scientific publications in nanotechnology indexed in the Scopus database, covering the period of $1982-2012$. The number of articles and conference papers in this period reached a total of 740,619 articles and conference papers indexed in that database (Scopus, 2013). It shows a rising curve of scientific literature on nanotechnology, especially in the last 10 years, period in which the number of scientific publications reached an annual average of 63,456 publications. It seems that the exponential growth after 1992 can be explained by the increased use of advanced techniques of dimensional metrology at nanoscale, such as scanning tunneling microscopy" (STM), which allowed studies of specific nanomaterials and nanoparticles. The evident advantages of STM are: atomic resolution and possibility of probing electronic states using I/V spectroscopy, but the major drawback is that it works only with conductive samples as tunneling.

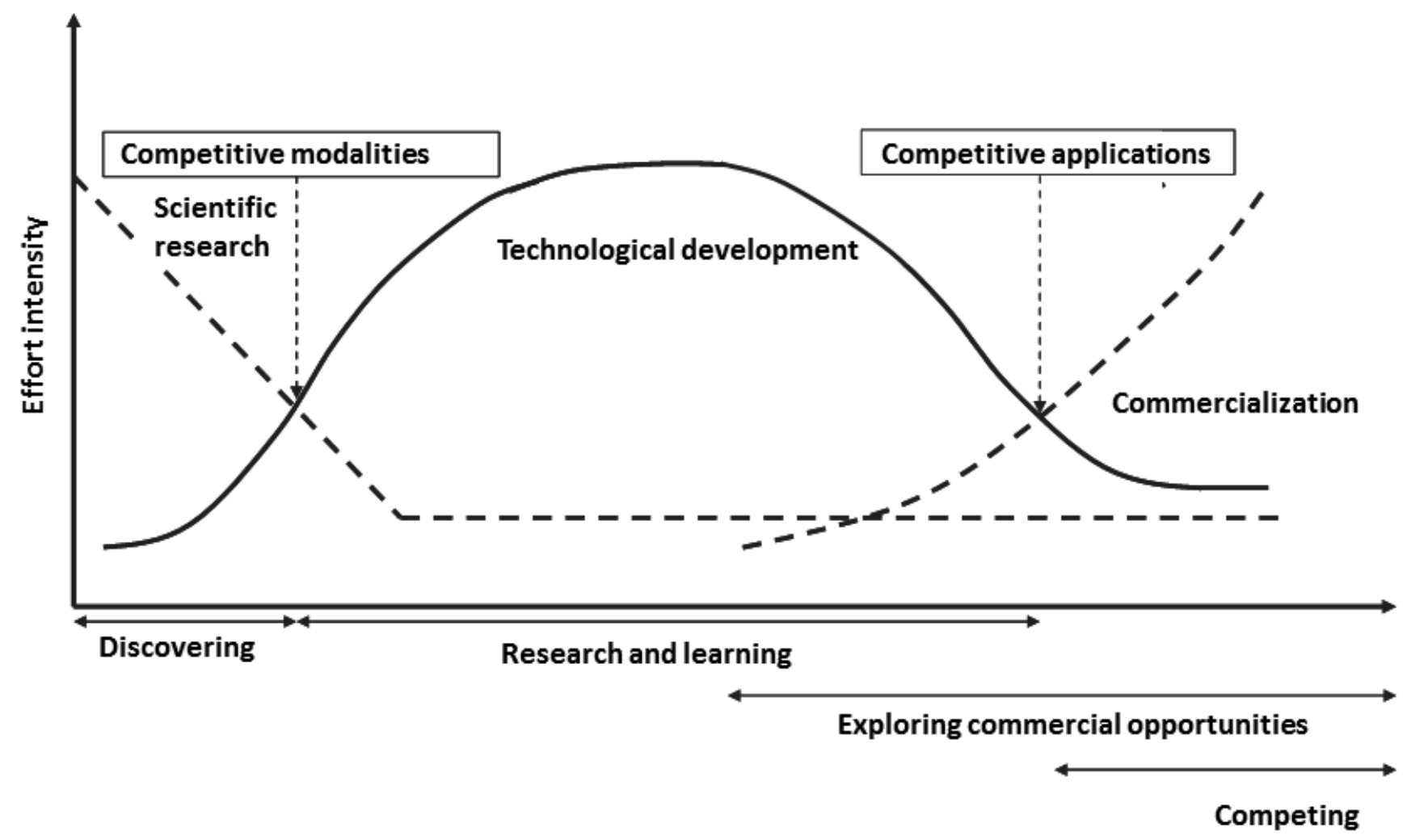

Figure I. Evolution of emerging knowledge until commercialization of competitive applications. Source: Day et al, 2003.

ISSN: 07 I8-2724. (http://www.jotmi.org)

Journal of Technology Management \& Innovation (C) Universidad Alberto Hurtado, Facultad de Economía y Negocios. 
Figure 3 represents the results of bibliometric analysis of the 740,619 scientific articles and conference papers, by revealing key subjects in the nanotechnology field. It can be observed that the subjects focused in our research are among the most important in the ranking of scientific output, namely, nanoparticles (I 32,555 publications); nanostructured materials $(123,378)$; nanostructures $(42,626)$ and nanocomposites $(36,609)$. It is important to mention the presence of four nanometrology techniques that will be discussed later in this article: (i) transmission electron microscopy $(65,048)$; (ii) scanning electron microscopy (54, 5 I9); (iii) X-ray diffraction; and (iv) atomic force microscopy (28,069 publications).

Following, we present the results of patent analysis related to nanotechnology, covering the same period of time: 1982-2012.

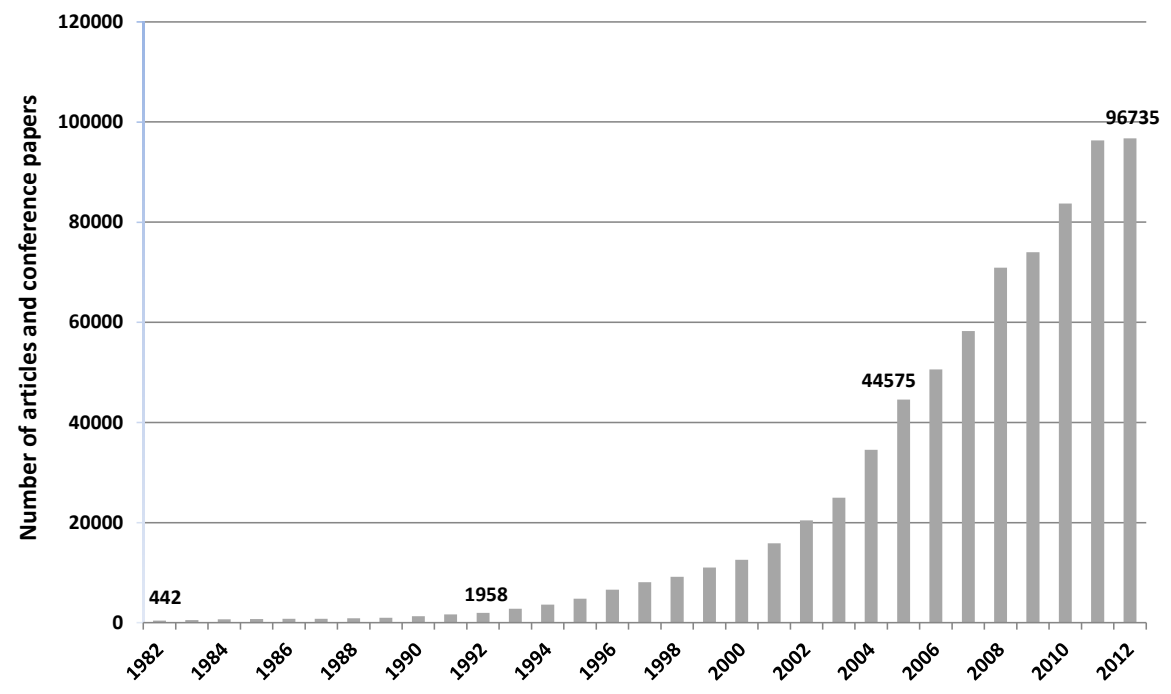

Figure 2. Evolution of the number of articles and conference papers in nanotechnology: 1982-2012

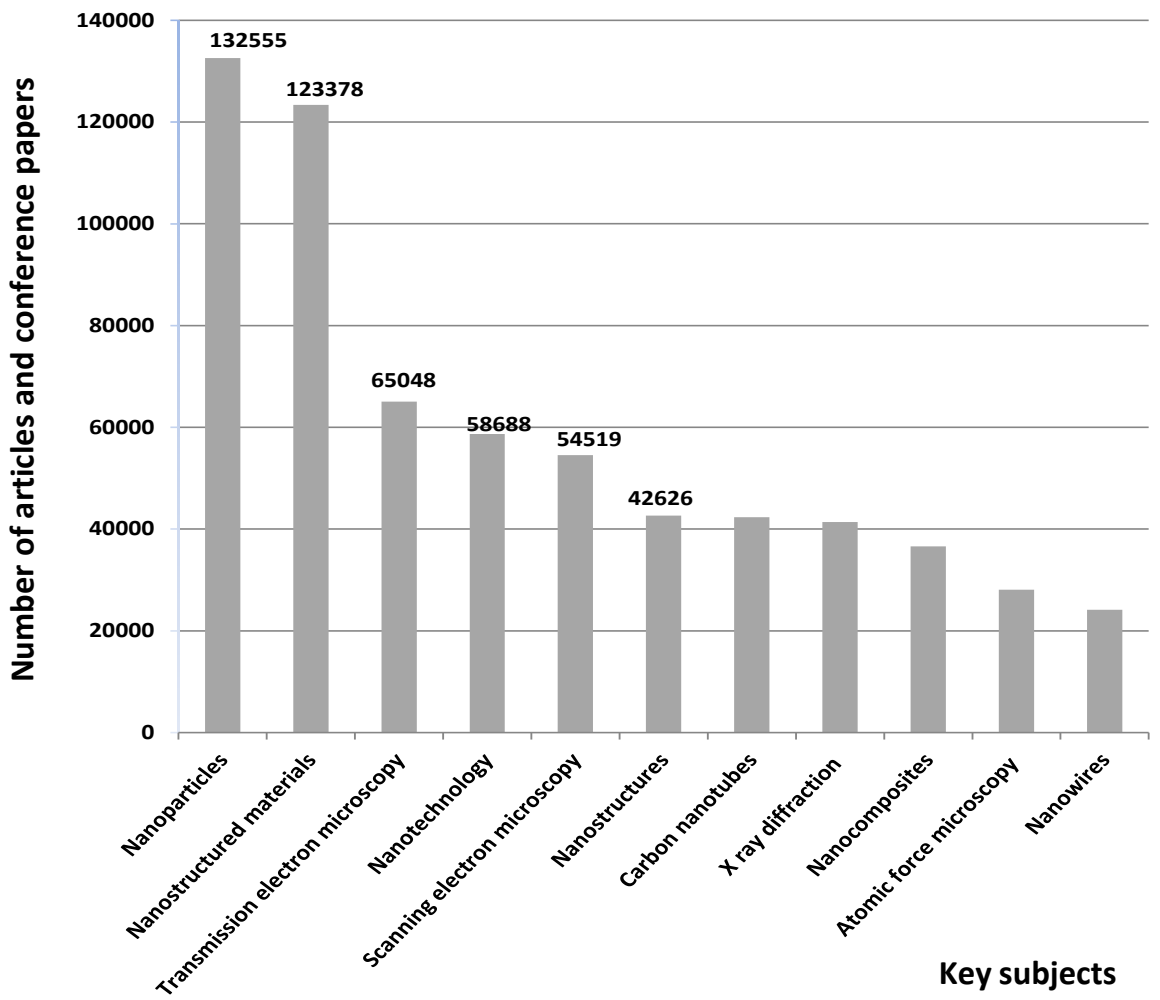

Figure 3. Number of articles and conference papers in nanotechnology, classified by key subjects: 1982-2012

ISSN: 07 I8-2724. (http://www.jotmi.org)

Journal of Technology Management \& Innovation (C) Universidad Alberto Hurtado, Facultad de Economía y Negocios. 


\section{Intellectual property}

The patent data on nanotechnology were gathered from Derwent Innovations Index, covering the period from 1982 to 2012 and totaling 154,672 patents.

Figure 4 shows the evolution of patent registration by organizations and individuals in this field in the mentioned period of time. These results are useful to visualize the dynamics of technological production on nanotechnology and lay grounds for reflections on use of bibliometric indicators and for ST\&I policy in nanotechnology.As in the case of scientific production, Figure 4 represents a rising curve, especially in the last 10 years, period in which the number of patents reached an annual average of 14,108 patents.

Table I presents the set of 154,672 patents, classified by subject area, indicating that the main areas are chemistry, engineering, instruments \& instrumentation, and polymer science.

The same set of patents was analyzed focusing on patent assignees, as shown in Table 2. The company which is in the first position is Hon Hai Precision Ind. Co. Ltd. with I,4I5 patents, followed by Samsung Electronics Co. Ltd. with I,0 4 patents. The remaining assignees in this ranking are five universities, two companies and one government agency.

\section{Research in Nanometrology and Standardization of Nanomaterials}

Since the publication of the study "Nanoscience and nanotechnologies: opportunities and uncertainties" by the Royal Society and the Royal Academy of Engineering in 2004, it appears that the number of studies, scientific research and initiatives related to nanometrology, standardization and regulation of nanotechnology have significantly evolved around the world (the Royal Society/Royal Academy of Engineering, 2004). We assume that many studies that have emerged in various academic centers at international level were largely encouraged by the challenges and statements discussed in this seminal comprehensive study. This section seeks to show evidences on the evolution of initiatives worldwide with respect to these three functions: nanometrology, standardization and regulation of nanotechnology.

A previous review of industrial and research-oriented nanometrology was covered by the work of Hasche et al (2000). According to this reference, research-oriented nanometrology is well established in research institutes and in industry. However, implementation of industrial nanometrology is still facing a variety of problems. The main differences between those two nanometrology streams can be identified in the area of precision, cost/efficiency and parameter types and of course conditions in which measurement takes place. Table 3 illustrates these main differences.

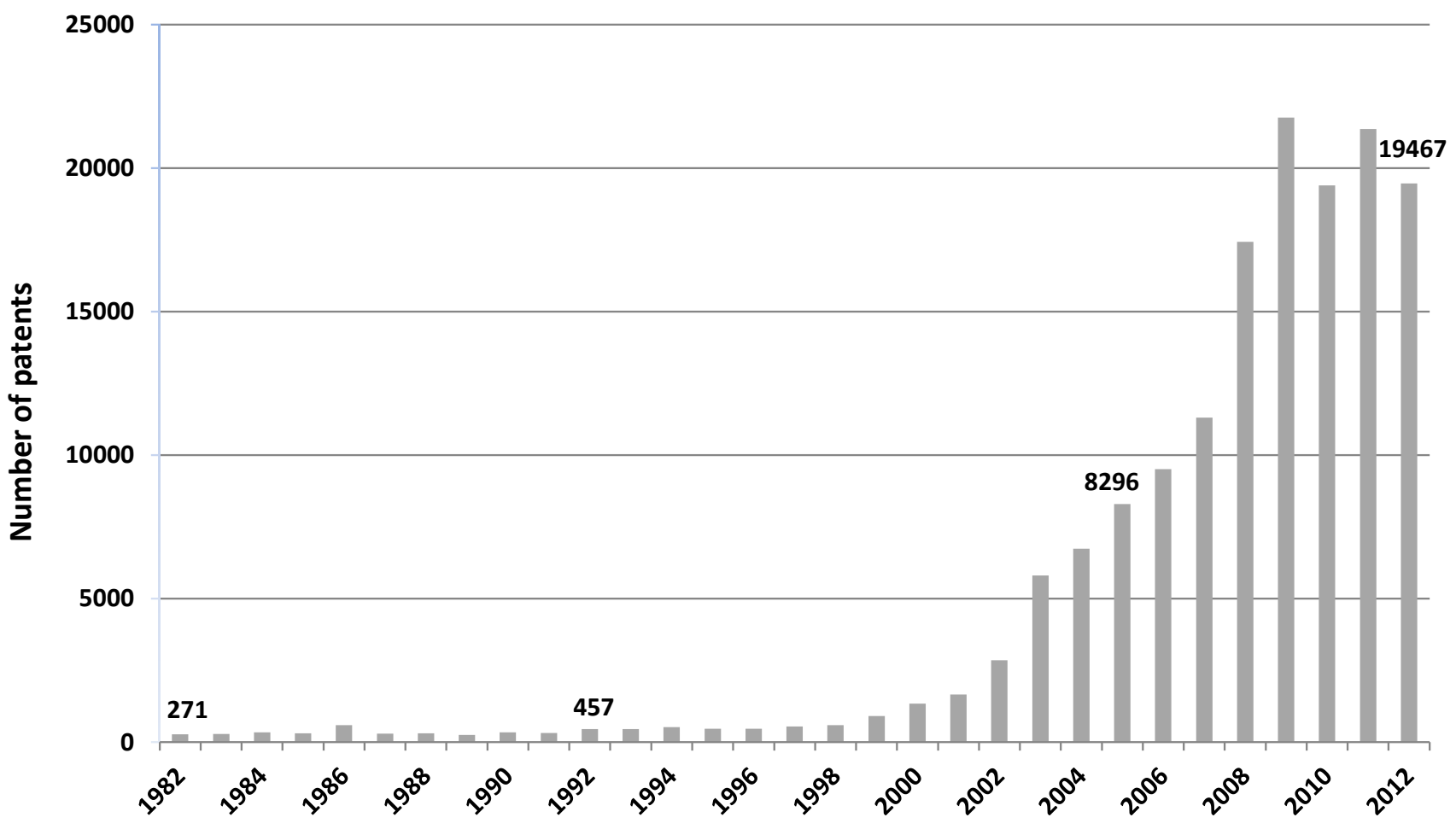

Figure 4. Evolution of number of patents in nanotechnology: 1982-2012

ISSN: 07 I8-2724. (http://www.jotmi.org)

Journal of Technology Management \& Innovation (c) Universidad Alberto Hurtado, Facultad de Economía y Negocios. 


\begin{tabular}{|l|l|l|}
\hline Area & $\begin{array}{l}\text { Number of } \\
\text { patents }\end{array}$ & Percentage of total (\%) \\
\hline Chemistry & 84,442 & 55 \\
\hline Engineering & 65,223 & 42 \\
\hline Instruments \& instrumentation & 56,415 & 36 \\
\hline Polymer science & 45,064 & 29 \\
\hline Pharmacology \& pharmacy & 17,130 & 11 \\
\hline Energy \& fuels & 11,948 & 8 \\
\hline Biotechnology \& applied microbiology & 9,127 & 6 \\
\hline Materials science & 9,017 & 6 \\
\hline $\begin{array}{l}\text { Imaging science \& photographic tech- } \\
\text { nology }\end{array}$ & 8,923 & 6 \\
\hline Metallurgy \& metallurgical engineering & 7,709 & 5 \\
\hline Total: I54,672 patents & & \\
\hline
\end{tabular}

Table I. Patents in nanotechnology, classified by subject areas: I982-20I2. Source: Direct search on Derwent Innovation Index Database

\begin{tabular}{|l|l|}
\hline Assignee Name & Number of patents \\
\hline Hon Hai Precision Ind. Co. Ltd. & $\mathrm{I}, 415$ \\
\hline Samsung Electronics Co. Ltd. & $\mathrm{I}, 014$ \\
\hline Univ. Qinghua & 977 \\
\hline Univ. Zhejiang & $79 \mathrm{I}$ \\
\hline Int. Business Machines Corp. & 574 \\
\hline Univ. California & 526 \\
\hline Hongfujin Precision Ind. Shenzhen Co. Ltd. & 508 \\
\hline Univ. Donghua & 508 \\
\hline Univ. Shanghai Jiaotong & 487 \\
\hline Commissariat Energie Atomique & 456 \\
\hline Total: 50,482 assignees & 154,672 patents \\
\hline
\end{tabular}

Table 2. Patents in nanotechnology, classified by patent assignees: $1982-2012$

\begin{tabular}{|l|l|}
\hline Research-oriented nanometrology & Industrial nanometrology. \\
\hline Requires highest precision - as possible. & $\begin{array}{l}\text { Requires highest effectiveness of measuring } \\
\text { systems. }\end{array}$ \\
\hline Vision driven observation - mostly. & Quantitative parameters need to be measured. \\
\hline Quantity of measurement parameters - as many as possible. & $\begin{array}{l}\text { Quantity of measured parameters need to be } \\
\text { acceptable. }\end{array}$ \\
\hline Measurement time and cost - are not so important. & Measurement time and cost - minimum. \\
\hline Significant importance of ambient conditions. & $\begin{array}{l}\text { Measurement under conditions in production } \\
\text { processes (rough conditions, affected by vibra- } \\
\text { tion, air pollution etc.). }\end{array}$ \\
\hline
\end{tabular}

Table 3. Research-oriented and industrial nanometrology. Source: Hasche et al (2000).

ISSN: 07 I8-2724. (http://www.jotmi.org)

Journal of Technology Management \& Innovation (C) Universidad Alberto Hurtado, Facultad de Economía y Negocios. 


\section{Research-oriented nanometrology Industrial nanometrology.}

Focusing on the second function - standardization - it is important to mention the importance of developing and establishing practical measurement standards (including reference samples) to apply practical nanometrology. According to the European Nanotechnology Gateway (2006), there are areas for which practical measurement standards are required, as follows:

- Written standards to be included in a format of ISO GPS - Geometric Product Specification;

- $\quad$ Scientific instrumentation including: scanning probe microscopes (including SNOM - Scanning);

- $\quad$ Near-field Optical Microscopy); SEM techniques; TEM; X-ray interferometry; XPS; VUV and EUV lithography; laser interference microscopy; focused ion beam (FIB); measurement of displacement; surface texture measuring;

- Validated measurement methods, in particular mask metrology; on-wafer metrology; test and development of calibration software for nanometrology;

- Measurement standards: surface standards; thickness standards for coating and painting, applicable also in depth profilometry used for microanalysis; methods of thickness measurement of thin layers from molecular scale to approximately $10 \mathrm{pm}$; characterization of topography and nanostructures on surfaces; characterization of surface modification on the nanoscale and in depth profilometry; $\mathrm{XYZ}$ standards for use in microelectronics and precision engineering and biochemistry; standards applicable in micro-hardness and other techniques for determination of mechanical properties; accurate force standards for measurements in the $\mathrm{nN}$-range; soft gauges for surface texture and similar software checks for other instrumentation and 3D structures for calibrating micro-/nano-CMMs; novel nanometrology of macroscopic physical, chemical and biological quantities;

Methods of measurement developed for conventional materials in many cases cannot be directly applied to nano-objects. For such cases special protocols need to be developed. Failure to do so may lead to serious mistakes in interpretation of data.

The MNT Roadmap in Metrology also indicates a need to further develop standards for nanometrology methods, especially those for evaluating physical and chemical properties. Standards for characterization of nanomaterials (e.g. particle size and distribution, morphology, degree of aggregation, solubility) are required to define the material, its suitability for given applications, and product consistency (European Nanotechnology Gateway, 2006, p. 16).

\section{Nanometrology, standardization and regulation of nanomaterials in Brazil: a proposal for an analytical- prospective model}

In this section, we propose an analytical-prospective model, designed as a tool to support decision making in issues concerning nanometrology, standardization and regulation of nanomaterials in Brazil. The model is addressed to the major stakeholders in the country, engaged in the development, production, formulation and commercialization of nanomaterials. In particular, to those members of the WG Regulatory Competitiveness Forum Nanotechnology Coordination, to the managers of the National R\&D Programme in Nanotechnology, in response to national public policies.

The model was designed for the effective development of nanometrology, standardization and regulation as a support for research and production of nanomaterials and also for the value chains enhanced by nanomaterials and nanomanipulated products. These three functions constitute the core of the analytical-prospective model here proposed.They are:

Nanometrology, specifically focusing on the use of dimensional, chemical and mechanical metrology techniques at nanoscale, applied to structured nanomaterials;

- $\quad$ Standardization, with emphasis on the adoption of standards for terminology and nomenclature; nanomaterials and nanocomposites; safety, environment and health; and performance of materials and products;

- $\quad$ Regulation, including issues related to the production and introduction of new nanomaterials into market; health and safety; manufacturers responsibility on the composition, quality and safety of products; consumer protection; environmental control and preservation; and waste management.

Among the international studies that formed the conceptual basis for the proposition of the analytical model, we highlight those mentioned in Table 4.

The proposed model comprises three levels of analysis, three dimensions, fifteen constructs and fourteen indicators. It resulted from an effort of identifying in the literature and empirical studies issues and concepts that should be considered from the perspective of the responsible development of nanomaterials. Accordingly, we present the three dimensions and the constructs identified in each dimension, without being exhaustive (Table 5). 


\begin{tabular}{|l|l|}
\hline Topic & Reference \\
\hline Definitions and basic concepts of nanotechnology and nanoscience & $\begin{array}{l}\text { The Royal Society/ The Royal Academy of } \\
\text { Engineering (2004). }\end{array}$ \\
\hline Nanotechnology value chain & Lux Research (2004). \\
\hline Metrology & $\begin{array}{l}\text { International Vocabulary of Metrology:VIM } \\
\text { (JCGM, 2008). }\end{array}$ \\
\hline $\begin{array}{l}\text { Nanometrology } \\
\text { Nanodimensional metrology } \\
\text { Nanochemical metrology } \\
\text { Metrology applied to structured nanomaterials }\end{array}$ & NanoStrand. Deliverable \# 7 (2006). \\
\hline $\begin{array}{l}\text { Standardization for nanotechnology } \\
\text { Regulation and auto-regulation initiatives for nanotechnology }\end{array}$ & $\begin{array}{l}\text { Observatorynano (20I0); NanoStrand. Delive- } \\
\text { rable \# 9 (2007). }\end{array}$ \\
\hline Regulation focusing on nanomaterials & Observatorynano (20I0). \\
\hline
\end{tabular}

Table 4. Studies and international benchmarks for the construction of the analytical model-prospective

\begin{tabular}{|c|c|c|}
\hline Dimension & Construct & Definition \\
\hline Nanometrology & $\begin{array}{l}\text { Dimensional nanometrology } \\
\text { Chemical nanometrology } \\
\text { Mechanical nanometrology } \\
\text { Metrology applied to structured nanomaterials }\end{array}$ & $\begin{array}{l}\text { Definitions from NanoStrand. Deliverab- } \\
\text { le \# } 7 \text { (2006). }\end{array}$ \\
\hline Standardization & $\begin{array}{l}\text { Terminology and nomenclature of nanotech- } \\
\text { nology } \\
\text { Nanomaterials } \\
\text { Nanocomposites } \\
\text { Safety, environmental protection, and occupa- } \\
\text { tional health standards concerning nanomateri- } \\
\text { als and nanoparticles production and usage. } \\
\text { Raw materials and products performance } \\
\text { specifications, focusing on nanomaterials and } \\
\text { nanoparticles. }\end{array}$ & $\begin{array}{l}\text { Definitions from NanoStrand. Deliverab- } \\
\text { le \# } 9 \text { (2007). }\end{array}$ \\
\hline \multirow[t]{4}{*}{ Regulation } & $\begin{array}{l}\text { Regulation regarding nanomaterials production } \\
\text { and entry to market. }\end{array}$ & Definitions from Frater et al. (2006). \\
\hline & $\begin{array}{l}\text { Safety and environmental regulation focusing } \\
\text { on nanomaterials and nanoparticles production } \\
\text { and usage. }\end{array}$ & \\
\hline & $\begin{array}{l}\text { Producer responsibility regarding composition, } \\
\text { quality, and safety conditions of nanoproducts. }\end{array}$ & \\
\hline & $\begin{array}{l}\text { Protection to consumers, focusing products } \\
\text { manufactured with nanomaterials and nanopar- } \\
\text { ticles. }\end{array}$ & \\
\hline
\end{tabular}

Table 5. Dimensions and constructs of the analytical-prospective model

ISSN: 07 I8-2724. (http://www.jotmi.org)

Journal of Technology Management \& Innovation (C) Universidad Alberto Hurtado, Facultad de Economía y Negocios. 
Figure 5 represents the components that integrate the model in a sequence of three modules: (i) module I - review of state-of-the-art in nanometrology, standardization and regulation of nanomaterials worldwide; (ii) module 2 - diagnosis of the current situation and identification of key challenges regarding these three functions within the Brazilian context, and (iii) module 3 - strategic roadmapping related to development trajectories of these technical functions in Brazil, indicating goals for short, medium and long term, considering a time horizon of 10 years.

The first module aims to review the state-of-the-art in nanometrology, standardization and regulation of nanomaterials worldwide, with a special attempt to identify metrologi$\mathrm{cal}$, regulatory and normative issues which are being analyzed worldwide. It seeks to identify: (i) nanometrology techniques that should be object of analysis; their stage of maturity and in which countries they are being developed or adopted; (ii) the standards which should be adopted during innovation cycle, production, storage, commercialization, and disposal of nanomaterials, and (iii) regulatory and legal mechanisms (already existing or under development) related to nanomaterials at international level.
For the first module, specifically for the submodule "stateof-the art of nanometrology techniques", we identified 5I techniques, being 16 associated to dimensional nanometrology; 12 regarding to chemical nanometrology; 7 to mechanical nanometrology, and 8 associated to metrology applied to structured nanomaterials. Information on these techniques is detailed in the report titled "State-of-art report on nanometrology" (NanoStrand, 2006). For the purpose of practical application of the proposed tool, it is recommended a permanent monitoring of international and national nanotechnology contexts, with an attempt to review systematically the state-of-the art of subfields here discussed.

With respect to the submodule "Standardization", we adopted the typology of standardization used throughout the NanoStrand Projet (2007). This typology was particularly relevant for the steps of survey research and construction of strategic roadmaps. We identified 33 subjects classified into the following categories: (i) terminology and nomenclature of nanotechnology (6 subjects), (ii) nanomaterials (8 subjects); (iii) nanocomposites (6 subjects); (iv) health, safety, and environment - HSE (7 subjects); (v) performance of materials and products, focusing on nanomaterials and nano-

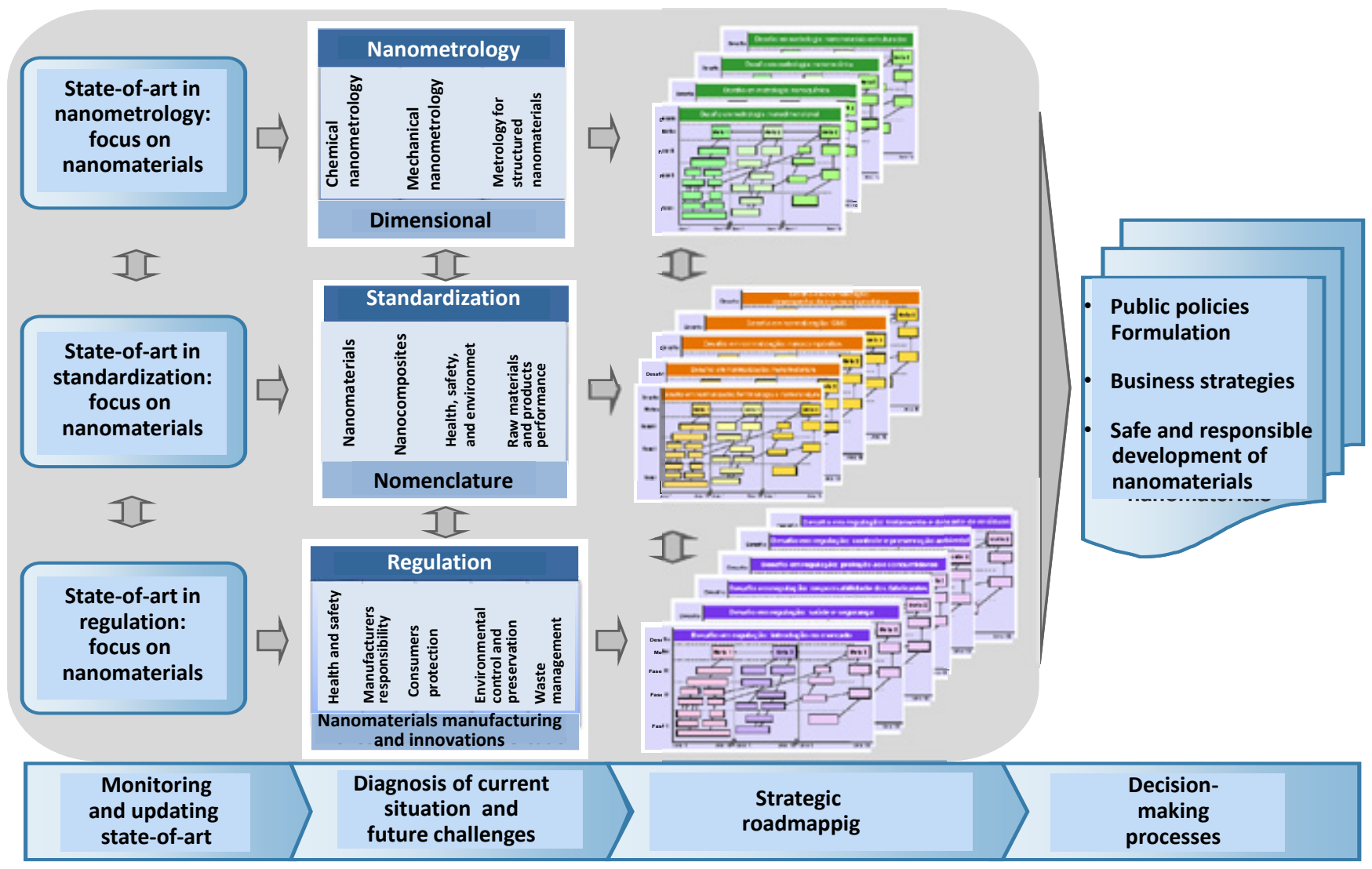

Figure 5. Schematic representation of the analytical-prospective model

ISSN: 07 I8-2724. (http://www.jotmi.org)

Journal of Technology Management \& Innovation (c) Universidad Alberto Hurtado, Facultad de Economía y Negocios. 
particles ( 6 subjects). It is important to mention that this typology is fully aligned with international standardization work conducted by ISO and IEC.

The submodule dedicated to the state-of-the-art of regulation concerning nanomaterials, we highlight the main regulatory issues that should be the object of analysis in the subsequent stages of the model application. An initial proposal based on ObservatoryNano (2010) and Frater et al (2006) included the following issues: (i) risk characterization; (ii) risk assessment; (iii) risk management; and (iv) current legal mechanisms related to each of the six fields covered. These fields are: (i) regulation of production and introduction of nanomaterials into markets; (ii) health and safety, focusing on nanomaterials and nanoparticles, (iii) manufacturers' responsibility regarding the composition, quality and safety conditions of products; (iv) consumer protection, focusing on products manufactured with nanomaterials and nanoparticles, (v) environmental control and preservation; and (vi) waste management. As in the previous submodules, it is recommended the permanent monitoring of the issues addressed here, from the perspective of future proposals for revision or consolidation of the regulatory framework relating to nanomaterials in Brazil.

The second module of the model is entitled "Diagnosis of the current situation and identification of key challenges" (See Figure 5). It constitutes the central part of the analytical-prospective model proposed here and includes the following items: (i) survey research objectives and goals; (ii) design of the survey questionnaire and definition of research contents; (iii) scope of the research, (iv) frequency; (v) statistical and analysis unit; (vi) classification of activities related to nanotechnology, (vii) method of gathering information, (viii) processing and analysis of information, and (ix) proposition of indicators. This module seeks to fulfill needs identified by the main actors of the National Innovation System in $\mathrm{Na}-$ notechnology, committed to the development, production and commercialization of nanomaterials aligned to safe and responsible principles (Brazil, 20I0).

The survey research aims to gather information on various aspects concerning the three functions of technological infrastructure - nanometrology, standardization and regulation - from Brazilian institutions and companies. This kind of information allows the building of indicators with international comparability, and strategic roadmaps for the Brazilian context. So, the survey questionnaire consists of four sections and respective issues, as described below:

- Section I - Identification: it refers to the identification of respondents, comprising issues about their affiliation; and roles that their organizations play, which are related to nanotechnology;
- $\quad$ Section 2 - Nanometrology: it comprises issues relating to nanodimensional, chemical and mechanical nanometrology, and also metrology applied to structured nanomaterials;

- $\quad$ Section 3 - Standardization: it addresses issues related to standards concerning nanotechnology nomenclature; nanomaterials, nanocomposites, safety, environment and health issues related to nanomaterials and nanoparticles; performance of nanomaterials and nanoproducts;

- $\quad$ Section 4 - Regulation: it refers to emerging questions about regulation of production and commercialization of nanomaterials; health and safety issues, focusing on nanomaterials and nanoparticles; manufacturers' responsibility on the composition, quality and safety of products; consumer protection; environmental control and preservation; and waste management regulation.

For their effective application in the future, a pretest with 20 experts in nanomaterials, was carried out during the period July - August 2010, intermittently and in accordance with the availability of respondents. The application of the questionnaire was virtual, i.e. experts could complete it using the internet. In total, eight completed questionnaires were returned from 20 questionnaires submitted. The pretesting responses confirmed the relevance of the proposed constructs and variables. After pretesting, the survey questionnaire was attached in its final format in a MSc. dissertation concluded in November 201 I in Brazil (Ledesma, 20 I I).

Table 6 shows the complete analytic grid, based on the conceptual proposal presented in Table 5 and also on the results of pretesting phase. The proposed questionnaire has potential application in: (i) major educational institutions, research and development centers (federal, state, municipal and private ones); (ii) departments of the National Institute of Metrology, Standardization and Industrial Quality (Inmetro); (iii) National Body of standardization (ABNT); (iv) network of laboratories accredited by Inmetro; and (v) research and development and production units of various nanomaterials companies in the country.

By way of illustration, for the purpose of building a cadastral database of potential respondents, we included: (i) companies registered in the National Register of Legal Entities (CNPJ) of the Ministry of Finance, whose activities are registered by the Brazilian Institute of Geography and Statistics (IBGE) as nanotechnology-related ones; (ii) affiliation of experts which are active in nanomaterials and nanometrology fields (recorded in Innovation Portal created and maintained by the Ministry of Science, Technology and Innovation (MCTI); (iii) institutions of research groups on nanomaterials, which are part of the Directory of Research Groups in Brazil, created and maintained by the National Council for Scientific and Technological Development (CNPq), and (iv)

ISSN: 07 I8-2724. (http://www.jotmi.org)

Journal of Technology Management \& Innovation (c) Universidad Alberto Hurtado, Facultad de Economía y Negocios. 
institutions and companies of experts who are developing nanotechnology and nanomaterials initiatives, funded by federal public authorities.

\section{Dimension}

Finally, the third module refers to the construction of strategic roadmaps concerning development and consolidation of the Brazilian technological infrastructure for research, production and commercialization of nanomaterials. It seeks to develop graphical representations that allow simplified sharing and effective communication on strategic goals related to nanometrology, standardization and regulation of nanomaterials in Brazil, from a long-term perspective. It is believed that, from the collective construction of strategic roadmaps, all joint efforts of mobilization, alignment and coordination of initiatives could be significantly facilitated. Summing up, the strategic roadmaps can provide: (i) a framework for thinking about the future developments concerning the three functions focused in this paper; (ii) a strategic structure of these functions; and (iii) action plans linked to subtopics (constructs) of each function, including indication of actors who should be involved in their implementation.

\begin{tabular}{|c|c|c|}
\hline Dimension & Construct & Indicators \\
\hline Nanometrology & $\begin{array}{ll}\text { - } & \text { Dimensional nanometrology. } \\
\text { - } & \text { Chemical nanometrology. } \\
\text { - } & \text { Mechanical nanometrology. } \\
\text { - } & \text { Metrology applied to structured nanomaterials. }\end{array}$ & $\begin{array}{l}-\quad \text { Frequency of use of a } \\
\text { given nanometrology technique. } \\
-\quad \quad \text { Fields of application of a } \\
\text { given nanometrology technique. } \\
-\quad \quad \text { Importance of application } \\
\text { of a given nanometrology technique. } \\
-\quad \text { Stage of nanometrologi- } \\
\text { cal infrastructure in the country in } \\
\text { relation to a given nanometrology } \\
\text { technique. }\end{array}$ \\
\hline Standardization & $\begin{array}{l}-\quad \text { Terminology and nomenclature of nanotechnology. } \\
-\quad \text { Nanomaterials. } \\
-\quad \text { Nanocomposites. } \\
-\quad \text { Safety, environmental protection, and occupational } \\
\text { health standards concerning nanomaterials and nanoparticles } \\
\text { production and usage. } \\
-\quad \quad \text { Raw materials and products performance specifica- } \\
\text { tions, focusing on nanomaterials and nanoparticles. }\end{array}$ & $\begin{array}{l}\text { - } \quad \text { Frequency of use of a } \\
\text { given standard. } \\
-\quad \quad \text { Fields of application of a } \\
\text { given standard. } \\
-\quad \quad \text { Importance of adoption of } \\
\text { a given standard. } \\
-\quad \text { Stage of national infra- } \\
\text { structure in relation to a given } \\
\text { standard. }\end{array}$ \\
\hline \multirow[t]{4}{*}{ Regulation } & $\begin{array}{l}\text { - Regulation regarding nanomaterials production and } \\
\text { entry to market. }\end{array}$ & $\begin{array}{l}\text { - Stage of risk characteriza- } \\
\text { tion in the country. } \\
-\quad \quad \text { Stage of risk assessment } \\
\text { in the country. } \\
-\quad \quad \text { Stage of risk management } \\
\text { in the country. } \\
-\quad \text { Existence of legal mecha- } \\
\text { nisms in the country concerning to } \\
\text { each construct. } \\
-\quad \quad \text { Importance of regulation } \\
\text { for the country. } \\
-\quad \text { Urgency of regulation. }\end{array}$ \\
\hline & $\begin{array}{l}\text { - Safety and environmental regulation focusing on nano- } \\
\text { materials and nanoparticles production and usage. }\end{array}$ & \\
\hline & $\begin{array}{l}\text { - Producer responsibility regarding composition, quality, } \\
\text { and safety conditions of nanoproducts. }\end{array}$ & \\
\hline & $\begin{array}{l}\text { - Protection to consumers, focusing products manufac- } \\
\text { tured with nanomaterials and nanoparticles. }\end{array}$ & \\
\hline
\end{tabular}

Table 6. The complete analytic grid, based on the conceptual proposal

ISSN: 07 I8-2724. (http://www.jotmi.org)

Journal of Technology Management \& Innovation (c) Universidad Alberto Hurtado, Facultad de Economía y Negocios. 


\section{Conclusions}

Assessing the situation of an emergent country in relation to nanometrology, standardization and regulation of nanomaterials under a systemic and integrated view, as proposed here, could be considered as an exploratory task. From this perspective, the analytical-prospective model for evaluating critical issues related to nanometrology, standardization and regulation of nanomaterials contributed to the advancement of knowledge on the purposeful influence of these technological functions in guiding and supporting the development of nanomaterials innovations.

Although it has embedded contributions from previous international studies and projects, thereafter, new elements were included, especially issues concerning regulation of nanomaterials. It is believed that the analytical-prospective model, which is intended to be flexible, dynamic and systemic, can be useful for managers of both private and public sectors, as well as for academic institutions, in order to improve their innovation strategies, the formulation of public policies and their empirical research, respectively.

For future studies and actions based on the results here presented, we propose:

- to disseminate the integrated model "nanometrology, standardization and regulation" within government agencies and institutions with potential interest in its implementation at national level;

- $\quad$ to apply the survey questionnaire within an expert population, which includes various actors of the National Innovation System in Nanotechnology, demonstrating its importance as a tool for decision support in the context of institutions and companies really interested in ethical and conscious development of nanomaterials;

- $\quad$ to use non-parametric statistical analysis for treatment and analysis of data collected by adopting factorial analysis. This approach can more objectively demonstrate the importance of the factors (constructs) for the development, production and commercialization of nanomaterials in Brazil, by assigning weights to the factors and performance indicators;

- to identify opportunities for replication of the proposed model in other fields of nanotechnology, such as nanobiotechnology, nanophotonics, nanoelectronics among others;

- $\quad$ to develop web applications to disseminate the use of the proposed model and its tools to other Latin American countries.

\section{References}

ABDI CGEE (2008). Agência Brasileira de Desenvolvimento Industrial. Centro de Gestão e Estudos Estratégicos. Estudo prospectivo em nanotecnologia: 2008-2025. http://www. mdic.gov.br. [Accessed April 19, 2013].

BRASIL (2005). Ministério do Desenvolvimento, Indústria e Comércio Exterior. MDIC. Programa Nacional de Nanotecnologia. http://www.mdic.gov.br. [Accessed April 19, 20I3].

BRASIL (20I0). Ministério do Desenvolvimento, Indústria e Comércio Exterior. MDIC. Ata da $4^{a}$ reunião do Grupo de Trabalho Marco Regulatório. Fórum de Competitividade de Nanotecnologia. São Paulo, 29 de abril de 2010. http://www. mdic.gov.br. [Accessed April 19, 20I3].

DAY, G.S., Schoemaker, P.J.H. (Eds.) (2000). Wharton on Managing Emerging Technologies (pp. I-23). New York, John Wiley \& Sons.

DOSI, G. (I082). Technological paradigms and technological trajectories. Research Policy, v.2, n. 3, p. I47-162.

EMERGNANO (2009). A review of completed and near completed environment, health and safety research on nanomaterials and nanotechnology. Defra Project CB0409. (concise report).

EUROPEAN COMISSION (2008). Commission recommendation of a code of conduct for responsible nanosciences and nanotechnologies research. EC, Brussels 02/02/2008.

EUROPEAN NANOTECHNOLOGY GATEWAY (2006). Eighth Nanoforum Report: Nanometrology. http://nanoforum.org. [Accessed April 19, 20I3].

FRATER, L., Stokes, E., Lee, R., Oriola, T. (2006). An overview of the framework of current regulation affecting the development and marketing of nanomaterials. ESRC Centre for Business Relationships Accountability Sustainability and Society. BRASS. Cardiff: Cardiff University.

HASCHE, K., Mirande, W., Wilkening, G. Dimensional measurements in the micro- and nanometer range: applications, challenges, state-of-the art. In: Proceedings of the 4th Seminar on Quantitative Microscopy, Bremerhaven:Wirtschaftsverlag NW, 2000.

JOINT COMMITTEE FOR GUIDES IN METROLOGY (2008). International vocabulary of metrology: basic and general concepts and associated terms (VIM). JCGM, 2008.

ISSN: 07I 8-2724. (http://www.jotmi.org) 
KUHN, T.S. (1962). The structure of scientific revolutions (Ist ed.). University of Chicago Press.

LEDESMA, A. R. G. (20I0). Nanometrology, standardization and regulation of nanomaterials in Brazil: a proposal for an analytical-prospective model. M.Sc. Dissertation. M.Sc Programme on Metrology, Quality and Innovation. Pontifical Catholic University of Rio de Janeiro.

LUX RESEARCH INC. (2004). Statement of findings: sizing nanotechnology's value chain. Executive summary. Oct 2004. 3I p.

NANOSTRAND (2007). Standardization related to research and development for nanotechnologies. NMP4CT-2006-033167. Deliverable number 9. Quantitative survey of European stakeholders.

NANOSTRAND. (2006). Standardization related to research and development for nanotechnologies. NMP4CT-2006-033167. Deliverable number 7. State-of-art report on nanometrology.

NATIONAL INSTITUTE FOR OCCUPATIONAL SAFETY AND HEALTH (2009). Approaches to safe nanotechnology: managing the health and safety concerns associated with engineered nanomaterials. Publication No. 2009-125.

OBSERVATORIO DE PROSPECTIVA TECNOLÓGICA INDUSTRIAL. OPTI. (2008). Aplicaciones Industriales de las nanotecnologías en España en el horizonte 2020. Madri: Fundación OPTI. 2008.

OBSERVATORYNANO (2010). Developments in Nanotechnologies Regulation and Standards - 2010. NMP - Nanosciences, Nanotechnologies, Materials and New Production Technologies.

PHAAL, R., Farrukh, C.J.P., Probert, D.R. (2004). Customizing roadmapping, Research Technology Management, v. 47, n.2, p. 26-37.

RINNE, M. (2004). Technology roadmaps: infrastructure for innovation, Technological Forecasting and Social Change, v.7I, n.I, p. 67-80.

SALERNO, M., Landonia, P., Vergantia, R. (2008). Designing foresight studies for nanoscience and nanotechnology (NST) future developments. Technological Forecasting and Social Change, v.75, n.8, p. $1202-1223$.

SCOPUS Database (2013). http://www.scopus.com/home. url. [Accessed April 19, 2013].
DERWENT INNOVATION INDEX (20I3). http://diipcs.webofknowledge.com. [Accessed April 19, 2013].

THE ROYAL SOCIETY, INSIGHT INVESTMENT, THE NANOTECHNOLOGY INDUSTRIES ASSOCIATION (NIA). (2008). Code of conduct for responsible nanotechnology; the responsible nano code. http://www.responsiblenanocode.org. [Accessed April 19, 20I3].

THE ROYAL SOCIETY;THE ROYAL ACADEMY OF ENGINEERING (2004). Nanoscience and nanotechnologies: opportunities and uncertainties, London: The Royal Society/ The Royal Academy of Engineering.

UNITED NATIONS EDUCATIONAL, SCIENTIFIC AND CULTURAL ORGANIZATION (2006). The ethics and politics of nanotechnology, Paris: Unesco, 2006.

ZWANENBERG, P. et al. (2008). How can regulation shape the direction of nanomaterials innovation? Discussion paper. Science \& Technology Policy Research (SPRU), Freeman Centre. University of Sussex, Brighton. 